\title{
Effect of Gd doping on Structural, Morphological and Magnetic Properties of Mn-Zn Soft Ferrites Nanoparticles
}

\author{
Anjali Shrivastava ( $\sim$ success.anjali208@gmail.com ) \\ Jiwaji University https://orcid.org/0000-0001-6313-9366 \\ Ashwani Kumar Shrivastava \\ Jiwaji University Faculty of Physical Sciences
}

\section{Research Article}

Keywords: Ferrites, XRD, SEM, VSM

Posted Date: May 10th, 2021

DOl: https://doi.org/10.21203/rs.3.rs-500764/v1

License: (c) (1) This work is licensed under a Creative Commons Attribution 4.0 International License.

Read Full License 


\title{
Effect of Gd doping on Structural, Morphological and Magnetic Properties of Mn-Zn Soft Ferrites Nanoparticles
}

\author{
Anjali Shrivastava*, A K Shrivastava \\ School of Studies in Physics, Jiwaji University, Gwalior \\ *success.anjali208@gmail.com
}

\begin{abstract}
Co-precipitation technique was adopted to synthesize gadolinium doped manganesezinc ferrite nano particles with varying concentration $0,0.1,0.2$ and 0.3. XRD patterns authenticated the ferrite innovate in the as-prepared samples. The lattice parameter, crystallite size, lattice strain and x-ray density has been calculated. The crystallite size is comes bent on be around $5 \mathrm{~nm}$. The FTIR spectra reveal that every one the functional groups are present within the material. SEM images are accustomed to indicate the morphological characteristics of the asprepared samples. Magnetic properties show the decrease in saturation magnetization from $37.57 \mathrm{emu} / \mathrm{g}$ to $30.15 \mathrm{emu} / \mathrm{g}$ with reference to increase in gadolinium doping from 0.1 to 0.3 .
\end{abstract}

Keywords: Ferrites, XRD, SEM, VSM

\section{INTRODUCTION}

Magnetic nanoparticles have attracted increasing interest in recent years in academic still as in technical fronts [1-6]. The magnetic properties of nanomaterial were reported to be modified than those of bulk materials. This is due to their large surface to volume ratio as compared to bulk material. Especially nano-magnetic particles have useful properties like spin canting, surface anisotropy, super- paramagnetic [7] etc. due to this, nano magnetic particles have remarkable electrical and magnetic properties and have wide selection of practical applications in information storage system, ferro fluid, magneto caloric refrigeration and magnetic diagnostics [8-10]. Particularly, Gd doped Mn-Zn ferrite are technologically important because of high pyro magnetic coefficient $(\partial \mathrm{M} / \partial \mathrm{T}) \mathrm{H}$ and includes a low curie temperature [11]. The doping of $\mathrm{Gd}^{3+}$ ions in $\mathrm{Mn}-\mathrm{Zn}$ ferrite improves the thermo-magnetic properties of material which might be useful for developing low Curie temperature ferro fluid. Several physical and chemical methods like ball milling, co-precipitation, sol-gel, hydrothermal, citrate precursor, modified oxidation, sono chemical reaction method etc. are reported within the literature [12-16] for the synthesis of nano magnetic particles, however the Gd ion doped $\mathrm{Mn}-\mathrm{Zn}$ ferrite nanoparticles have not yet been prepared by these methods [17].

In the present investigation, nanoparticles of $\mathrm{Mn}_{0.5} \mathrm{Zn}_{0.5} \mathrm{Gd}_{\mathrm{x}} \mathrm{Fe}_{2-\mathrm{x}} \mathrm{O}_{4}(\mathrm{x}=0,0.1,0.2$ and $0.3)$ were prepared using chemical co-precipitation method and also the structural and magnetic properties are studied. 


\section{EXPERIMENTAL PROCESS}

\subsection{Materials:}

Manganese chloride tetra hydrate $\left(\mathrm{MnCl}_{2} \cdot 4 \mathrm{H}_{2} \mathrm{O}\right)$, iron (III) chloride $\left(\mathrm{FeCl}_{3}\right)$, zinc nitrate hexahydrate $\left(\mathrm{Zn}\left(\mathrm{NO}_{3}\right) \cdot 6 \mathrm{H}_{2} \mathrm{O}\right)$ and gadolinium oxide $\left(\mathrm{Gd}_{2} \mathrm{O}_{3}\right)$ were used as the primary materials for the synthesis. Required weights of all the primary agents were dissolved the distilled water. $\mathrm{HNO}_{3}$ was used to dissolve $\mathrm{RE}$ oxide. $\mathrm{NaOH}$ was used as a precipitating agent. All regents that as used were of analytical grade and used without any further purification.

\subsection{Synthesis of Nanoparticles}

Nano crystalline Gd doped Mn-Zn ferrites are synthesized by co-precipitation method. In perfect stoichiometric proportions manganese chloride tetra hydrate $\left(\mathrm{MnCl}_{2} \cdot 4 \mathrm{H}_{2} \mathrm{O}\right)$, iron (III) chloride $\left(\mathrm{FeCl}_{3}\right)$, zinc nitrate hexa-hydrate $\left(\mathrm{Zn}\left(\mathrm{NO}_{3}\right) \cdot 6 \mathrm{H}_{2} \mathrm{O}\right)$ and gadolinium oxide $\left(\mathrm{Gd}_{2} \mathrm{O}_{3}\right)$ were taken from their molar solutions. Sodium hydroxide solution was added in the solution with constant stirring. $\mathrm{pH}$ of the samples was maintained at 10. To stop the agglomeration of the nanoparticles a surfactant coating of oleic acid was made to the individual particles by adding oleic acid to the solution mixture during precipitation of particles Reaction time was 90 minutes at $80^{\circ} \mathrm{C}$ and precipitates were allowed to settle down at room temperature. Then the precipitated particles were centrifuged and washed several times with double distilled water to remove the salt residues and other impurities. The prepared precipitated particles then dried at room temperature. The dried material was crushed to powder using pestle-mortar. Now the crushed material powder was annealed at $200^{\circ} \mathrm{C}$ for 4 hours.

\subsection{Characterization of Nanoparticles}

The synthesized samples were characterized for structural properties using X-ray diffraction technique (XRD Rigaku Miniflex 600). FTIR spectra were recorded by using a Perkin Elmer IR spectrometer. SEM studies were performed on a ZEISS ULTRA PLUS scanning electron microscope. The magnetic properties of the as-prepared samples were studied using VSM (Lake Shore Cryotronics 7400-S).

\section{RESULTS and DISCUSSION:}

\subsection{X-ray Diffractometer}

X-ray diffraction of as synthesized $\mathrm{Mn}_{0.5} \mathrm{Zn}_{0.5} \mathrm{Gd}_{\mathrm{x}} \mathrm{Fe}_{2-\mathrm{x}} \mathrm{O}_{4}$ ( $\mathrm{x}=0,0.1,0.2$ and 0.3) nano particle powder samples has been performed for the structural characteristics namely crystallite size, lattice parameter, crystallite phase, lattice strain and X-ray density of as prepared. The lattice parameters were calculated using the interplaner distance, ' $d$ ' values and the respective (hkl) parameters. X- ray diffraction patterns of undoped and Gadolinium doped Mn-Zn ferrites with 
their tentative indexing are shown in Fig. 1. These pattern exhibits all the major peaks related to spinel structure without any impurity. XRD spectrum indicates that (311) is a prominent peak.
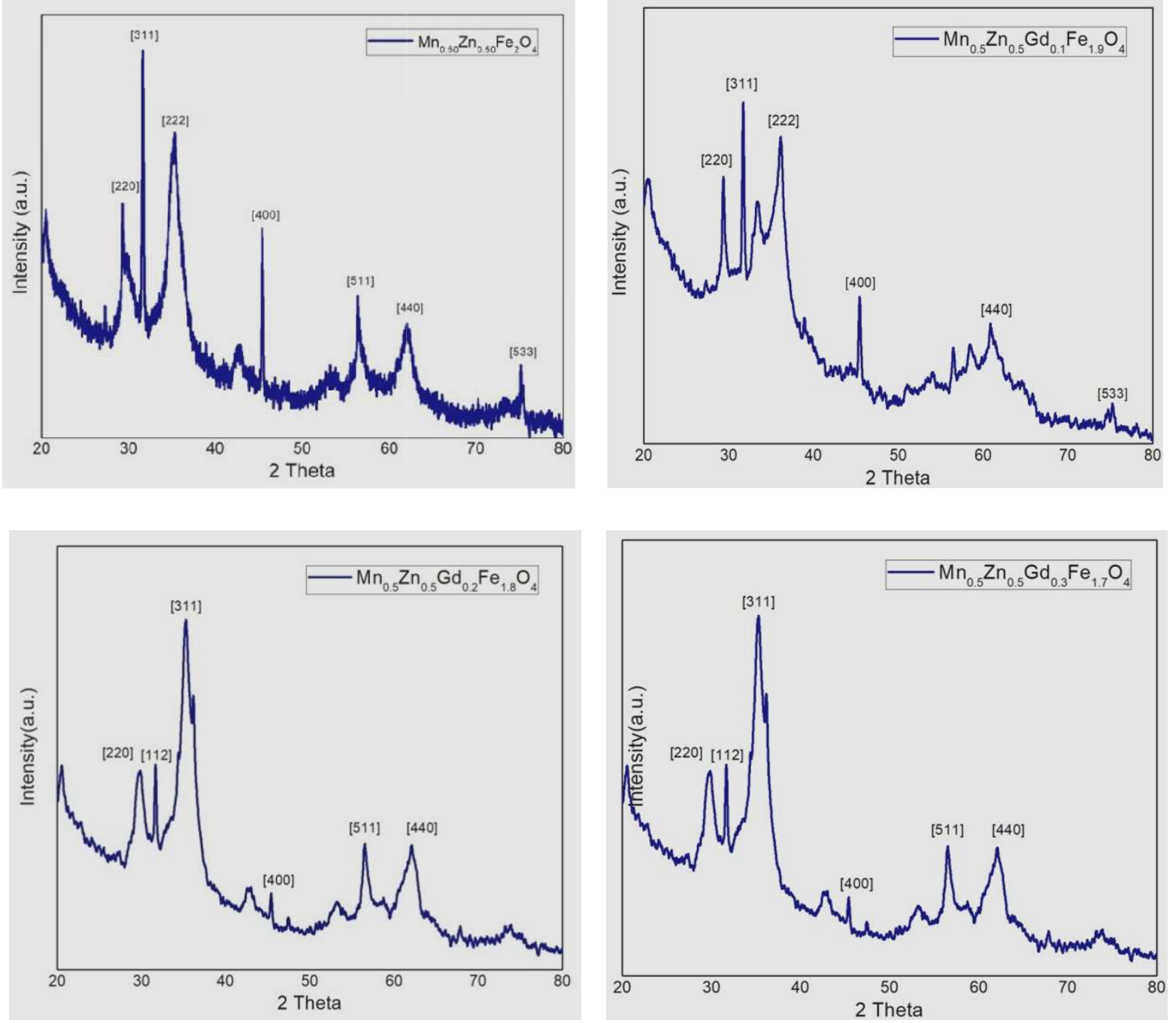

Fig 1. XRD pattern of Pure and Doped Mn-Zn Ferrite Powder

From the full width at half maxima (FWHM) of peaks, the mean size of the crystals was estimated by using Scherrer's equation given below:

$$
D_{X R D}=\frac{k \lambda}{\beta \cos \theta}
$$

where, $D_{\text {XRD }}$ is the mean dimension of the crystallites, $\mathrm{k}$ is Scherrer's constant taken to be $0.9, \lambda$ is the $\mathrm{x}$-ray wavelength $\left(\lambda=1.5406 \mathrm{~A}^{\circ}\right), \beta$ is the broadening of the peak width of half maximum, and $\theta$ is the Bragg's diffraction angle.

The lattice parameter of as-prepared samples was calculated by considering cubic crystal structure, from the plane (311) main peak of spinel structure using the Bragg's equation:

$$
a=d_{h k l} \sqrt{h^{2}+k^{2}+l^{2}}
$$


where $d_{h k l}$ is the interplaner distance, "a" is lattice parameter, and ' $h$ ', ' $k$ ', ' 1 ' are plane indices. The $\mathrm{X}$ - ray density $\rho_{\mathrm{x}}$ is determined using the equation [18]:

$$
\rho_{x}=\frac{Z M}{N_{A} V}
$$

where $Z=8$ (the number of atoms in cubic structure), $N_{A}$ is Avogadro number, $M$ is molecular weight and $\mathrm{V}$ is volume of the cubic unit cell: $\mathrm{a}^{3}$

The average crystallite size, lattice parameter, strain, x-ray density and interplaner spacing have been calculated using XRD data are given in Table 1.

From the XRD data table it is clear that the crystallite size is decreasing with the doping of gadolinium. The lattice parameter is increasing with doping of gadolinium; it might be due to the difference between the ionic radii of host and doping element. The X-ray density is increased with the doping of gadolinium, it indicates that with the doping of $\mathrm{Gd}$, the electron density of the sample increased.

Table 1: Values of crystallite size (D), lattice Parameter (a), X-ray density ( $\rho$ ) and lattice Strain ( $\varepsilon$ ) for $\mathrm{Mn}_{0.5} \mathrm{Zn}_{0.5} \mathrm{Gd}_{\mathrm{x}} \mathrm{Fe}_{2-\mathrm{x}} \mathrm{O}_{4}$

\begin{tabular}{lcccc}
\hline Composition & $\mathbf{D}(\mathbf{n m})$ & $\mathbf{a}(\overline{\mathbf{A}})$ & $\rho\left(\mathbf{g m} / \mathbf{c m}^{\mathbf{3}}\right)$ & $\boldsymbol{\varepsilon}$ \\
\hline $\mathrm{Mn}_{0.5} \mathrm{Zn}_{0.5} \mathrm{Fe}_{2} \mathrm{O}_{4}$ & 6.60 & 9.3741 & 4.7735 & 1.6635 \\
$\mathrm{Mn}_{0.5} \mathrm{Zn}_{0.5} \mathrm{Gd}_{0.1} \mathrm{Fe}_{1.9} \mathrm{O}_{4}$ & 5.85 & 9.3654 & 7.3307 & 1.5044 \\
$\mathrm{Mn}_{0.5} \mathrm{Zn}_{0.5} \mathrm{Gd}_{0.2} \mathrm{Fe}_{1.8} \mathrm{O}_{4}$ & 1.61 & 9.3960 & 7.2595 & 7.5332 \\
$\mathrm{Mn}_{0.5} \mathrm{Zn}_{0.5} \mathrm{Gd}_{0.3} \mathrm{Fe}_{1.7} \mathrm{O}_{4}$ & 3.12 & 8.4514 & 9.9758 & 2.8408 \\
& & & & \\
\hline
\end{tabular}

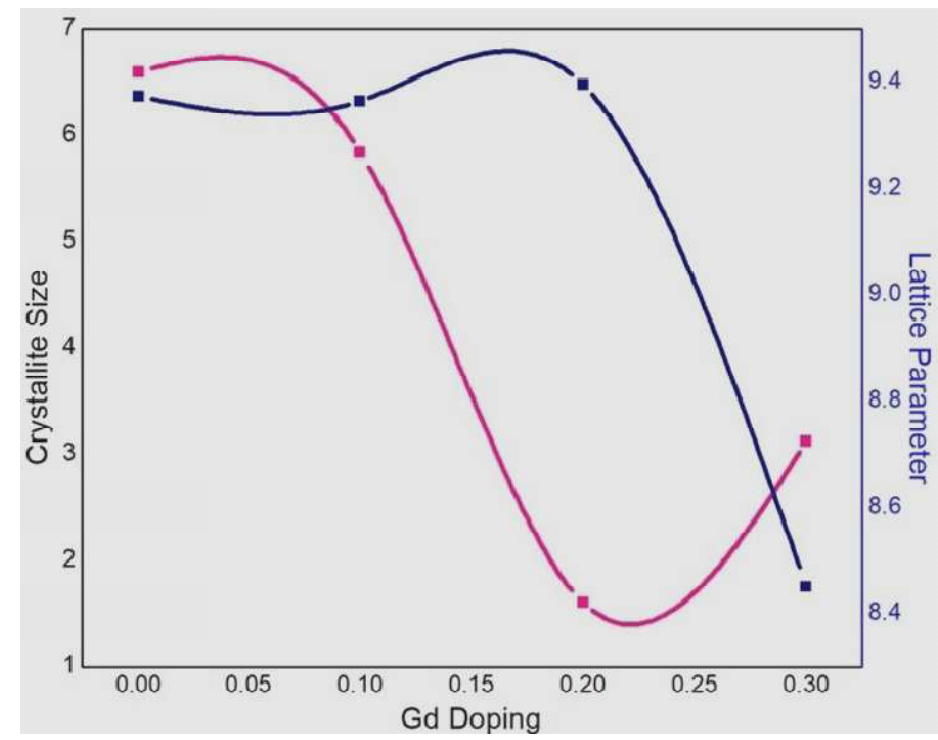

Fig 2: Variation of crystallite size and lattice parameter with "Sm" ion concentration 


\subsection{FTIR Spectrometry}

The FTIR spectra of these samples were recorded over the range of 500-4000 $\mathrm{cm}^{-1}$ and are shown in figure 3. Characteristic absorption peaks are clearly observed at around 2920, 2850, 1730, $1560,1380,1217$ and $610 \mathrm{~cm}^{-1}$. A broad absorption band appearing at around $3420 \mathrm{~cm}^{-1}$ in FTIR spectra is the characteristic of absorbed water (O-H stretching) which get slightly disappeared with the increase in gadolinium doping. In the figure we can show that the gadolinium demobilize the peak observed at $1730 \mathrm{~cm}^{-1}$ corresponds to aldehyde carbonyl $(\mathrm{HC}=\mathrm{O})$ group. Peaks at $2900 \mathrm{~cm}^{-1}$ and $2850 \mathrm{~cm}^{-1}$ are due to $\mathrm{C}-\mathrm{H}$ stretching and at $1560 \mathrm{~cm}^{-1}$ is for $\mathrm{C}=\mathrm{C}$ stretching. The absorption peaks at around $1380 \mathrm{~cm}^{-1}$ and $1217 \mathrm{~cm}^{-1}$ are due to C-O stretching. The absorption peaks at around $610 \mathrm{~cm}^{-1}$ are for $\mathrm{C}-\mathrm{H}$ bending.

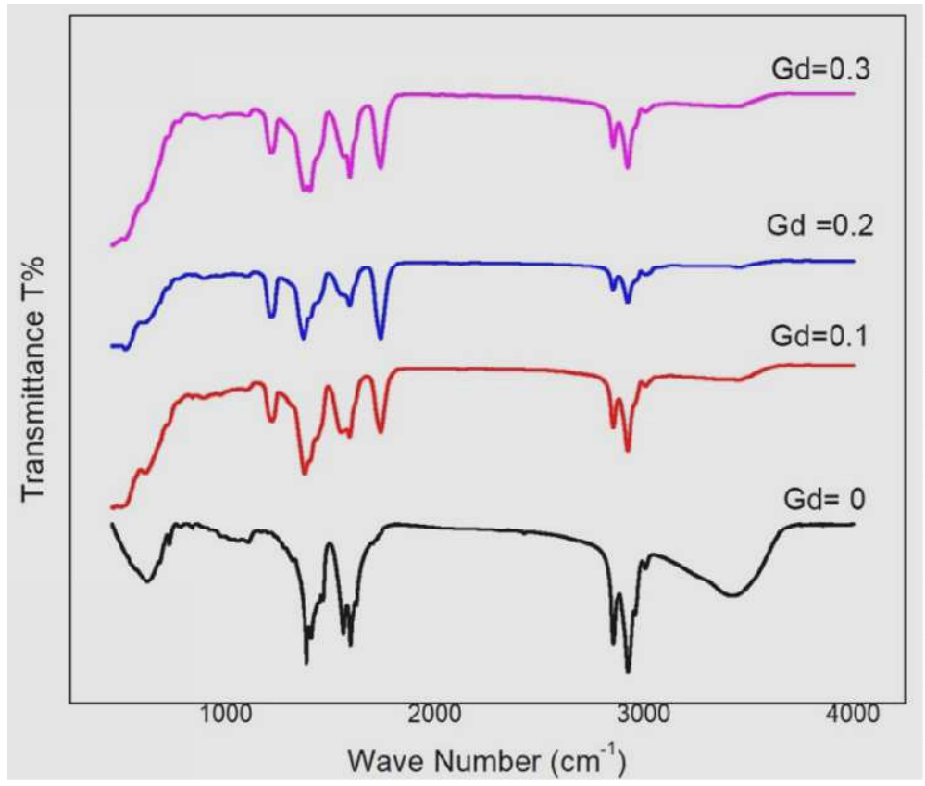

Fig 3. FTIR spectra of $\mathrm{Mn}_{0.5} \mathrm{Zn}_{0.5} \mathrm{Gd}_{\mathrm{x}} \mathrm{Fe}_{2-\mathrm{x}} \mathrm{O}_{4}$ samples

\subsection{Scanning Electron Microscope}
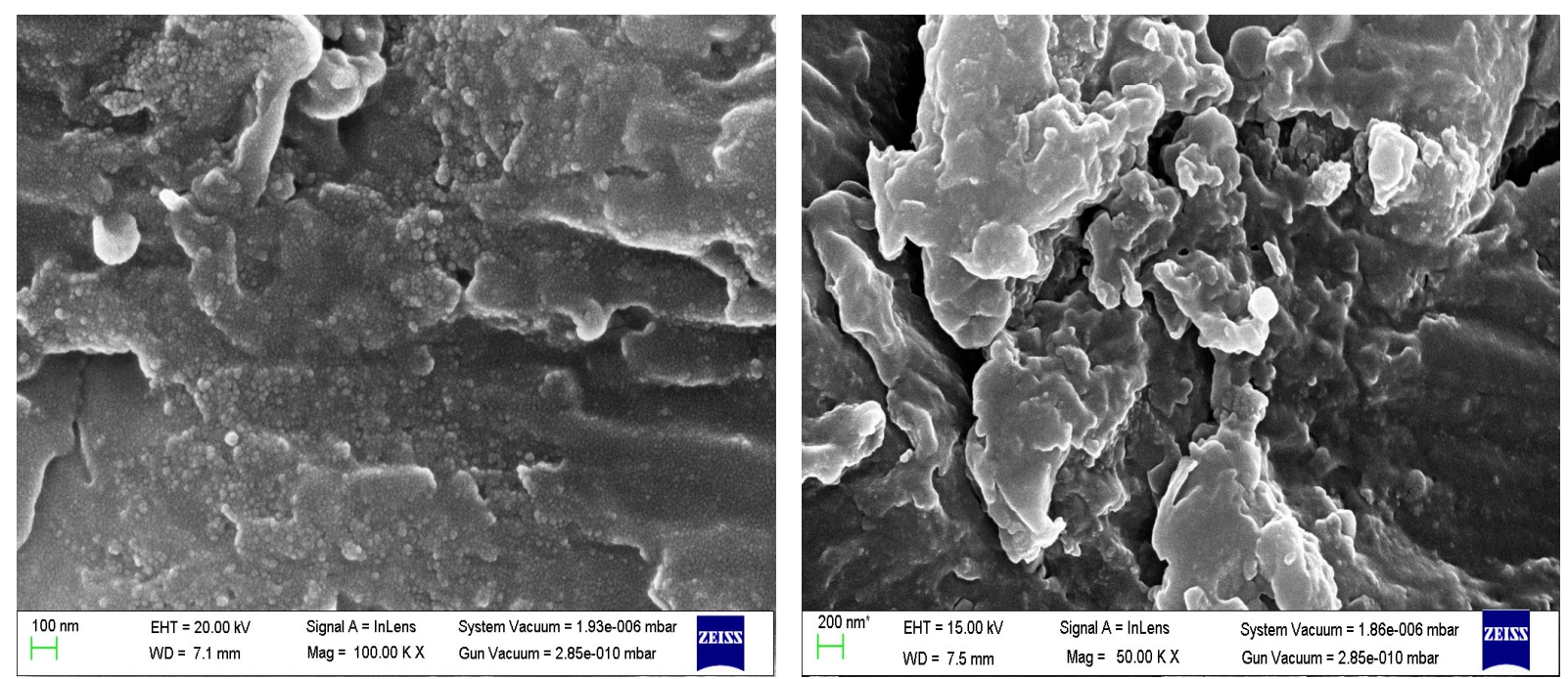

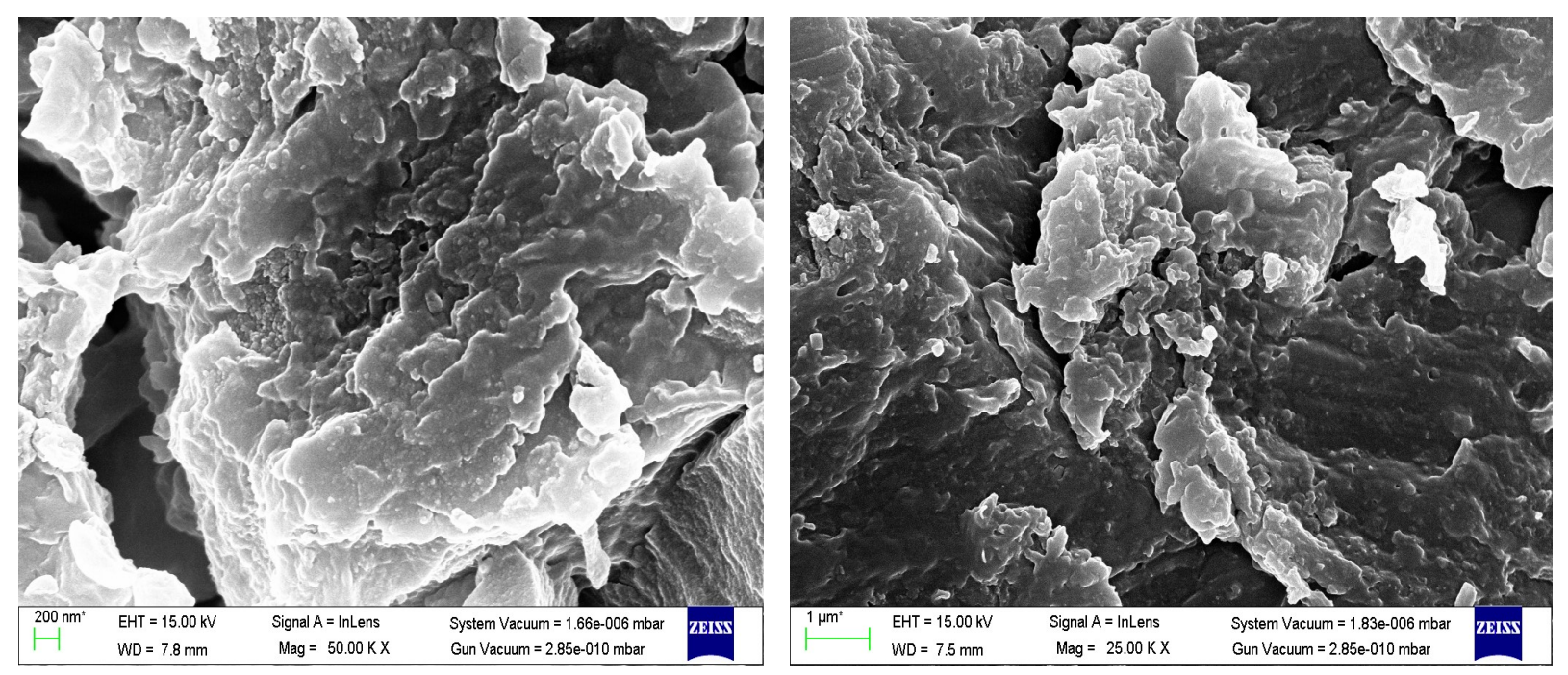

Fig 4: SEM images of as prepared samples

Scanning electron microscopy has been used to obtain the morphological details of the developed Gadolinium ion doped Mn-Zn ferrite nanoparticles. The SEM pictures of the $\mathrm{Mn}_{0.5} \mathrm{Zn}_{0.5} \mathrm{Gd}_{\mathrm{x}} \mathrm{Fe}_{2-\mathrm{x}} \mathrm{O}_{4}$ samples are taken at different magnifications. It is seen that on the doping of rare earth gadolinium ion the particles get agglomerated.

\subsection{EDAX}

From EDAX Studies, the traces of impurities and other elements are not identified. The observed composition ratios are consistent with expected composition ratio. This indicates that the expected stoichiometric under preparation is well maintained in the samples prepared using the co-precipitation technique.

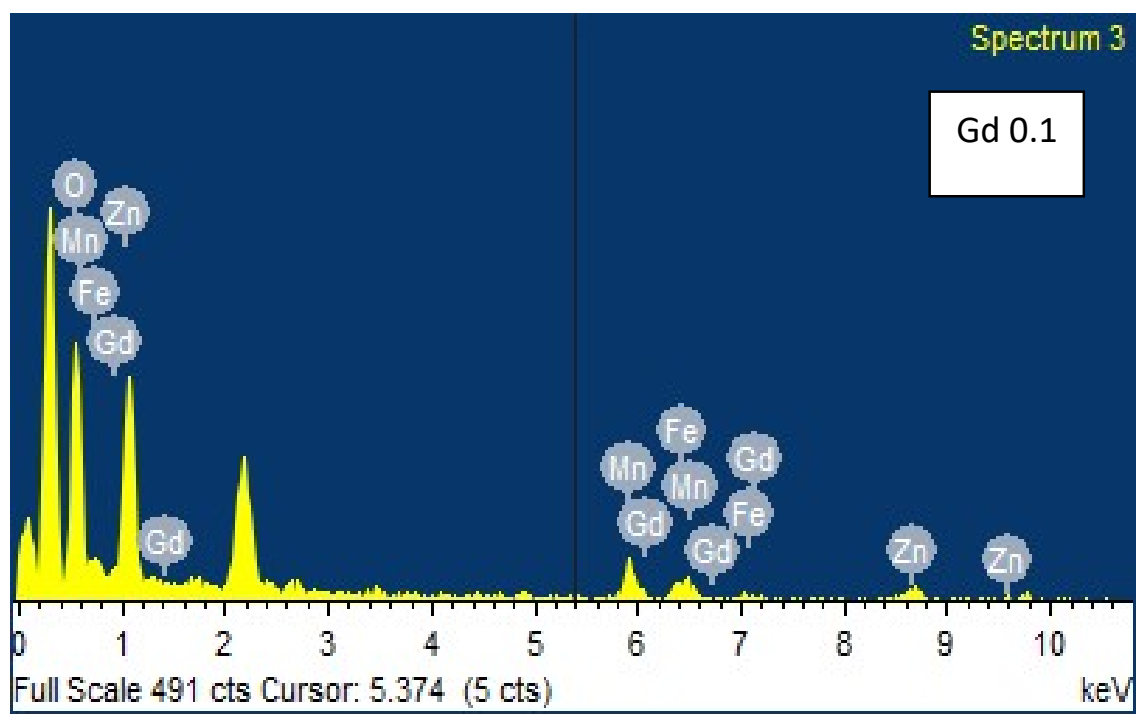



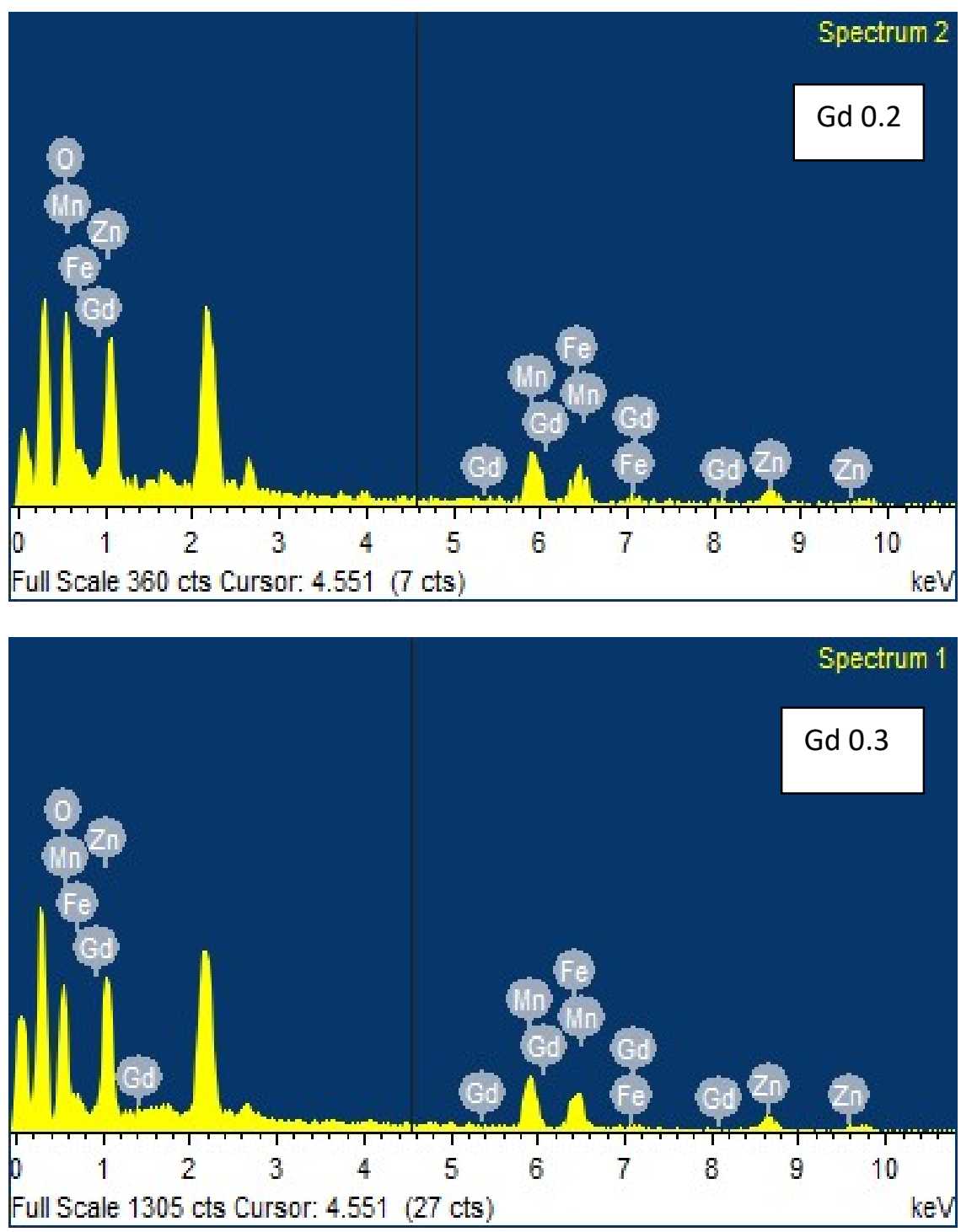

Fig 5: EDAX studies for pure and Gd doped Materials

\subsection{Hysteresis Measurements}

Magnetic measurements were carried out of the as-prepared samples at room temperature by using vibrating sample magnetometer (VSM). The Saturation magnetization $\left(\mathrm{M}_{\mathrm{S}}\right)$, Remanent magnetization $\left(\mathrm{M}_{\mathrm{r}}\right)$ and coercivity $\left(\mathrm{H}_{\mathrm{C}}\right)$ were evaluated from these measurements and given in the Table 2. Fig. 5 shows the magnetic characteristics of $\mathrm{Mn}_{0.5} \mathrm{Zn}_{0.5} \mathrm{Gd}_{\mathrm{x}} \mathrm{Fe}_{2-\mathrm{x}} \mathrm{O}_{4}$ nano ferrites samples which indicate that the magnetization first increase with the gadolinium doping and further increase in doping reduces the magnetization. This decrease in Ms with rare earth doping is due to lower magnetic ordering from the localized $4 f$ electrons of rare earth ions from which the magnetic moments originates. So $\mathrm{Gd}^{3+}$ substitution can be considered as a non-magnetic ion substitution in octahedral B-site. So this reduces the exchange interaction between A and B sites which results in decrease of magnetization [11,19]. It shows the ferromagnetic nature of the as prepared material. 


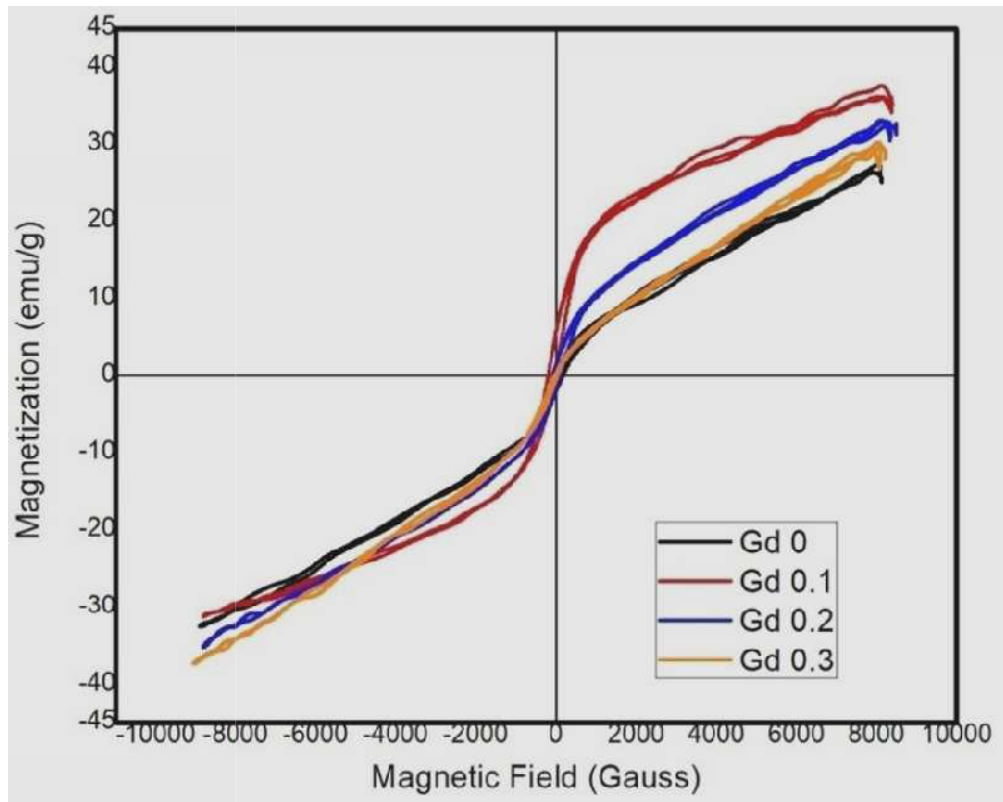

Fig.5: M-H curve for as prepared samples

Table 2: Magnetic Measurement of $\mathrm{Mn}_{0.5} \mathrm{Zn}_{0.5} \mathrm{Gd}_{\mathrm{x}} \mathrm{Fe}_{2-\mathrm{x}} \mathrm{O}_{4}$ samples.

\begin{tabular}{lccc}
\hline Composition & $\begin{array}{c}\text { Ms } \\
\text { (emu/g) }\end{array}$ & $\begin{array}{c}\mathbf{H}_{\mathbf{c}} \\
\text { (Gauss) }\end{array}$ & $\begin{array}{c}\mathbf{M}_{\mathbf{r}} \\
\text { (emu/gm) }\end{array}$ \\
\hline $\mathrm{Mn}_{0.5} \mathrm{Zn}_{0.5} \mathrm{Fe}_{2} \mathrm{O}_{4}$ & 27.28 & 35.64 & \\
$\mathrm{Mn}_{0.5} \mathrm{Zn}_{0.5} \mathrm{Gd}_{0.1} \mathrm{Fe}_{1.9} \mathrm{O}_{4}$ & 37.57 & 200.05 & 0.41 \\
$\mathrm{Mn}_{0.5} \mathrm{Zn}_{0.5} \mathrm{Gd}_{0.2} \mathrm{Fe}_{1.8} \mathrm{O}_{4}$ & 33.09 & 80.08 & 5.68 \\
$\mathrm{Mn}_{0.5} \mathrm{Zn}_{0.5} \mathrm{Gd}_{0.3} \mathrm{Fe}_{1.7} \mathrm{O}_{4}$ & 30.15 & 27.77 & 1.52 \\
& & & 0.32
\end{tabular}

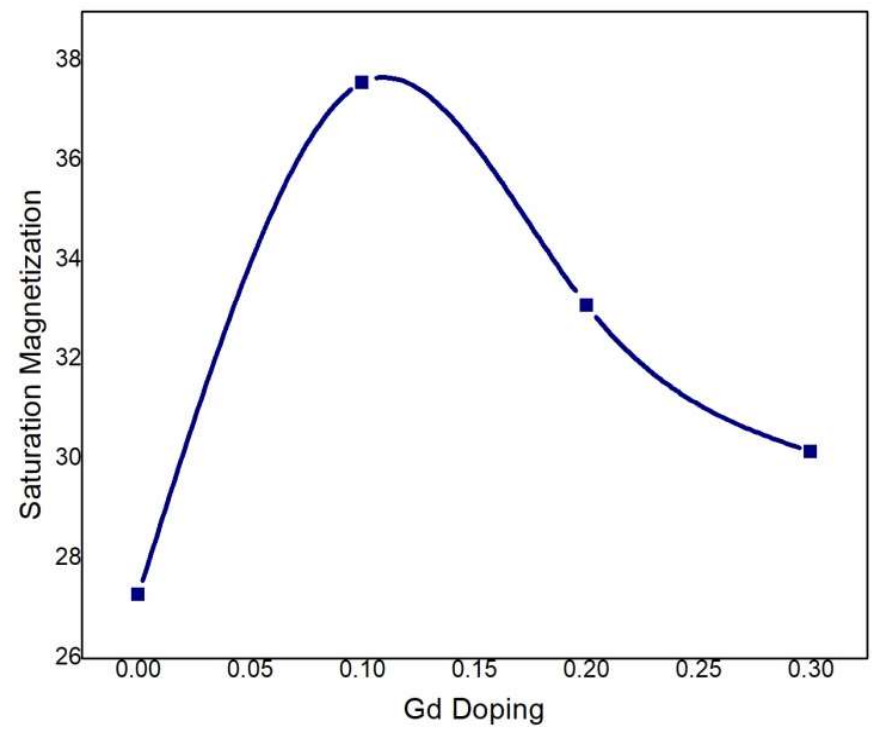

Fig 6: Concentration dependence of Saturation Magnetization 


\section{Conclusion}

Undoped and gadolinium doped $\mathrm{Mn}-\mathrm{Zn}$ nano particles have been synthesized using coprecipitation method. The as-prepared nano magnetic particles were characterized for their structural, morphological and magnetic properties. In comparison to undoped ferrite nano particles, the crystallite size decreases with gadolinium doping. The surface morphology of these fine particles shows the presence of ultra fine particles when doped with gadolinium. The saturation magnetization increases while we dope the material with gadolinium also the prepared magnetic materials are ferromagnetic in nature.

\section{Acknowledgement:}

We are thankful to IIT Roorkee for the SEM -EDAX and VSM characterization.

\section{REFERENCES:}

1. J.P. Chen, C.M.Sorensen, K.J.Klabunde, G.C.Hadjipanayis, E.Devlin and A. Kostikas, Phys.Rev.B:Condens.Matter 54 (1996) 9288.

2. R.P. Pant, M.Arora, A.Rana, V.Kumar and A.Kumar, J.Magn.Magn.Mater.322 (2010) 3688.

3. B. Issa, I.M. Obaidat, B.A. Albiss and Y.Haik, Int.J. Mol. Sci.14 (2013)21266.

4. N.Kumari, V.Kumar and S.K.Singh, Ceram.Int. 40 (2014) 12199.

5. K.D.Hyun, E.N.David, T.J.Duane and S.B.Christopher, J.Magn.Magn. Mater. 320 (2008)2390.

6. A.T.Ngo, M.P.Pileni, J.Phys.Chem.B105 (2001)53.

7. V. Kumar, A.Rana, M.S.Yadav, R.P.Pant, J.Magn.Magn.Mater.320(2008)1729.

8. M. Zheng, X.C.Wu, B.S.Zou, Y.J.Wang, J.Magn.Magn.Mater. 183 (1998)152.

9. A.C. F.M.Costa, E.Tortella, M.R.Morelli, R.H.G.A.Kiminami, J.Magn.Magn.Mater.256 (2003) 174 .

10. A.Verma, T.C.Goel, R.G.Mendiratta, M.I.Alam, Mater.Sci. Eng., B60 (1999)156.

11. E. Calderon-Ortiz, O.P.Perez, P.Voyles, G.Gutierrez, M.S.Tomar, Microelectron.J. 40 (2009)677.

12. R.V.Upadhyaya, R.V.Mehta, K.Parekh, D.Srinivas, R.P.Pant, J.Magn.Magn.Mater. 201 (1999) 129.

13. I.E.Candish, B.H.Kear, B.K.Kim, Co.Nanostruct.Mater. 1 (1992) 119.

14. G.Skandan, H.Hahn, M.Roddy, W.R.Carnnon, J.Am.Ceram.Soc. 77 (1994) 1706.

15. R.P.Pant, R.M.Krishna, D.P.Singh, D.Srinivas, R.V.Mehta, J.Magn.Magn.Mater.164 (1996) 143.

16. K.Raj, B.Moskowitz, S.Tsuda, J.Eng.Mater.Sci 11 (2004)241.

17. A. Kumar, P. S. Rana, M. S. Yadav and R. P. Pant, Ceramics International 41(2015) 1297.

18. B.D.Cullity, Elements of X-rays Diffraction, second ed., Addison Wesley, Publishing Co., Philippines 338 (1978).

19. S.Thankachan, M.Kurian, D.S.Nair, S.Xavier and E.M.Mohammed, International Journal of Engineering Science and Innovative Technology (IJESIT) 3(4) (2014) 529. 
Figures
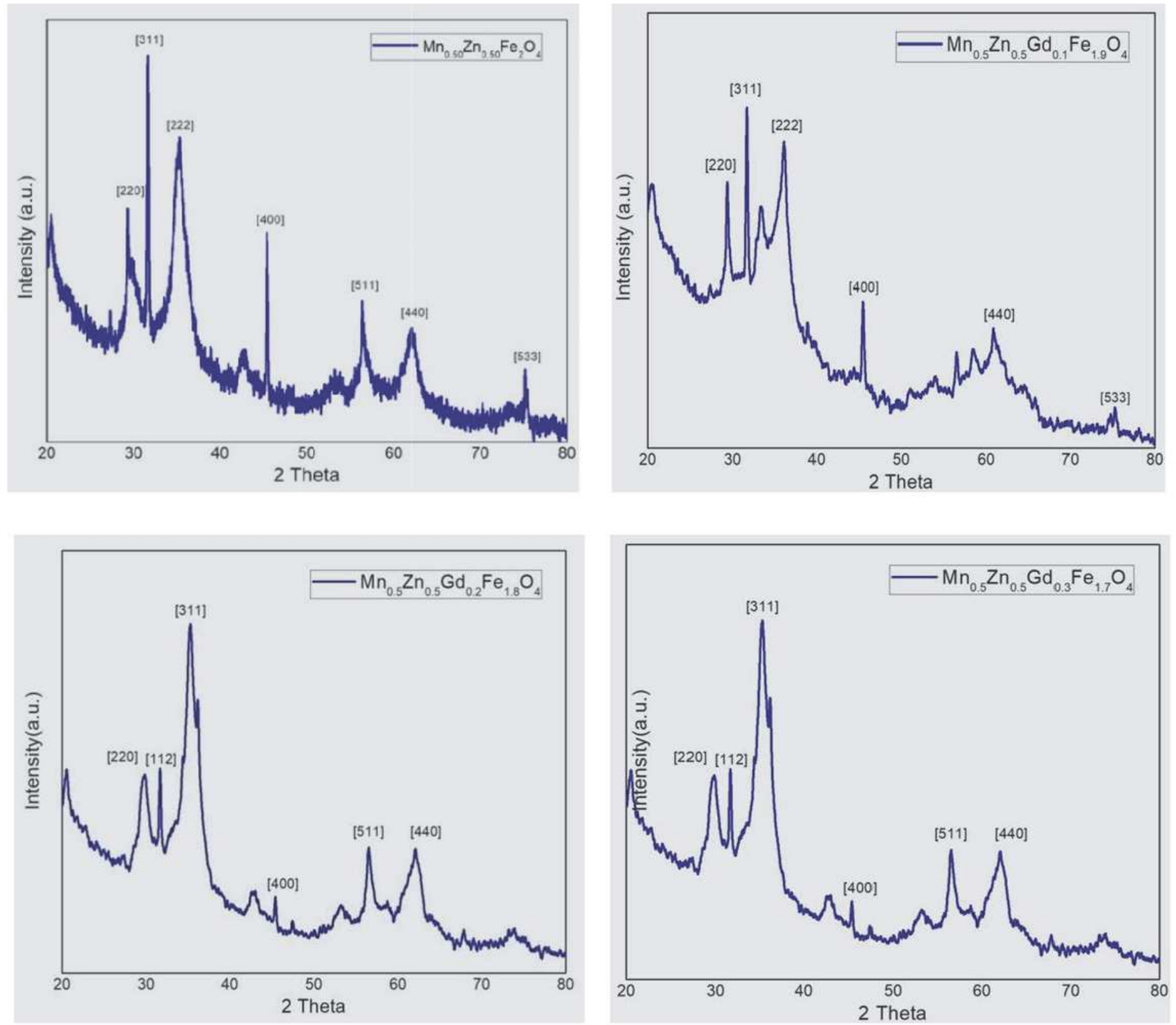

Figure 1

XRD pattern of Pure and Doped Mn-Zn Ferrite Powder 


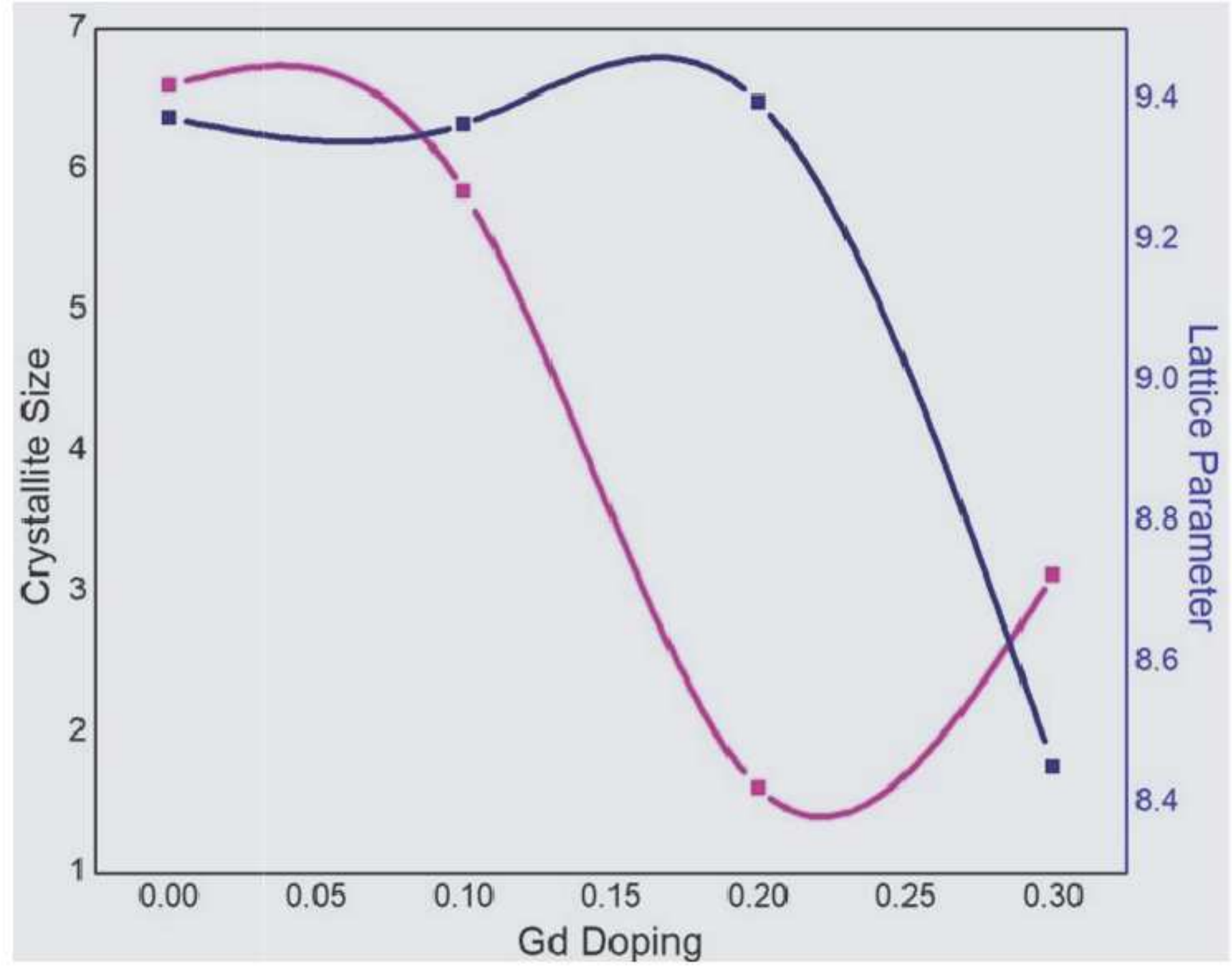

Figure 2

Variation of crystallite size and lattice parameter with "Sm" ion concentration 


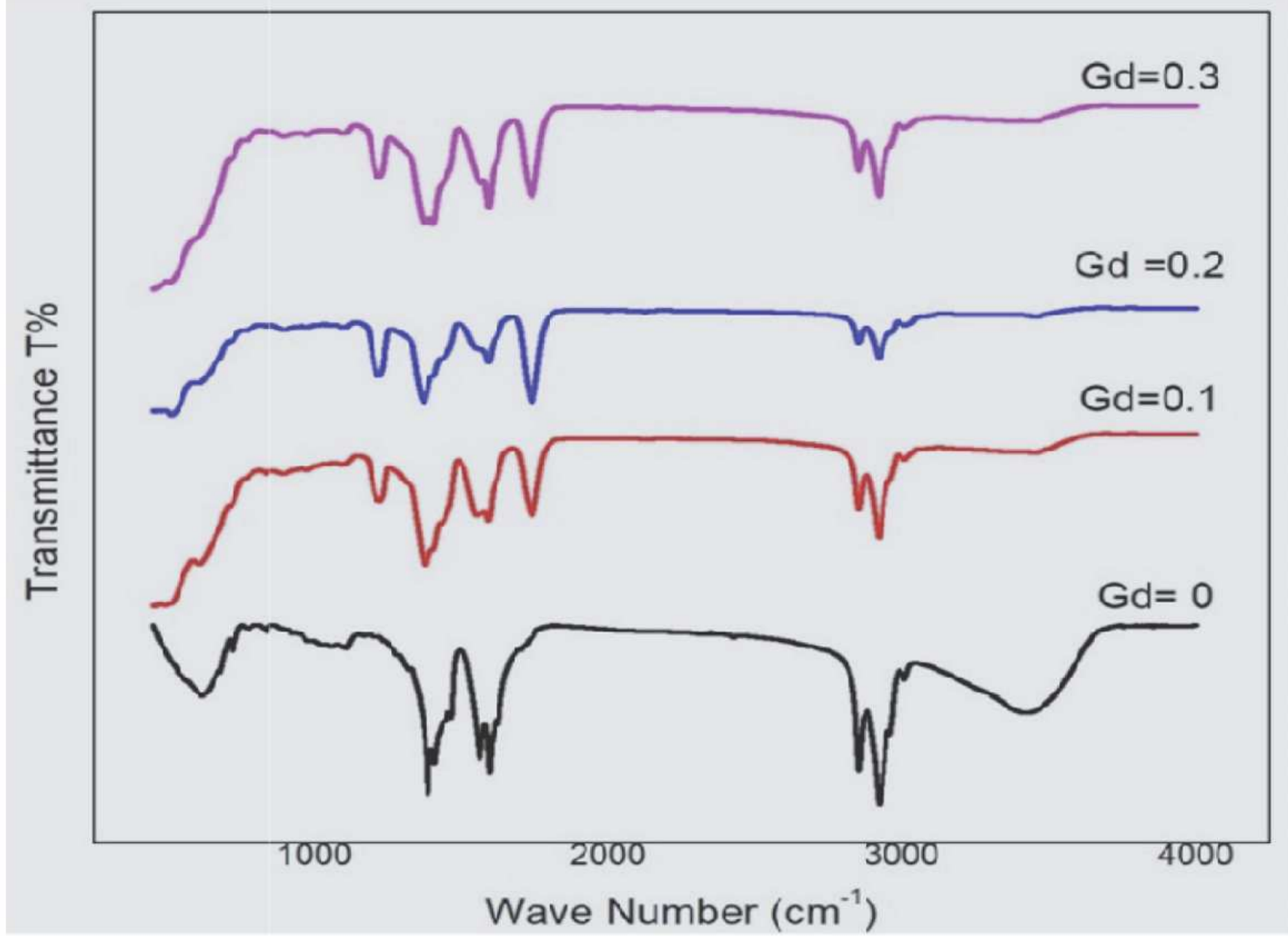

Figure 3

FTIR spectra of Mn0.5Zn0.5GdxFe2-xO4 samples 

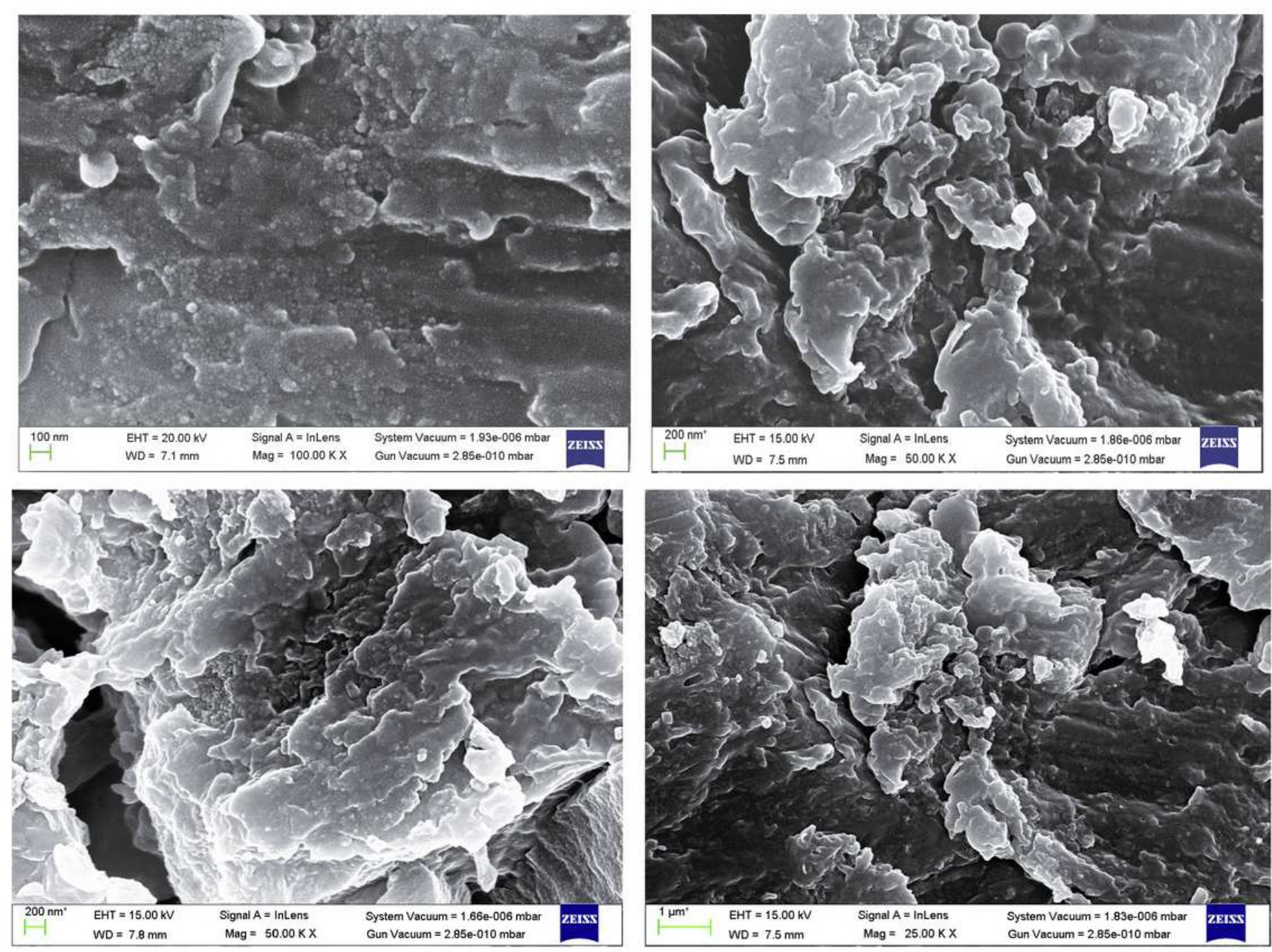

Figure 4

SEM images of as prepared samples 

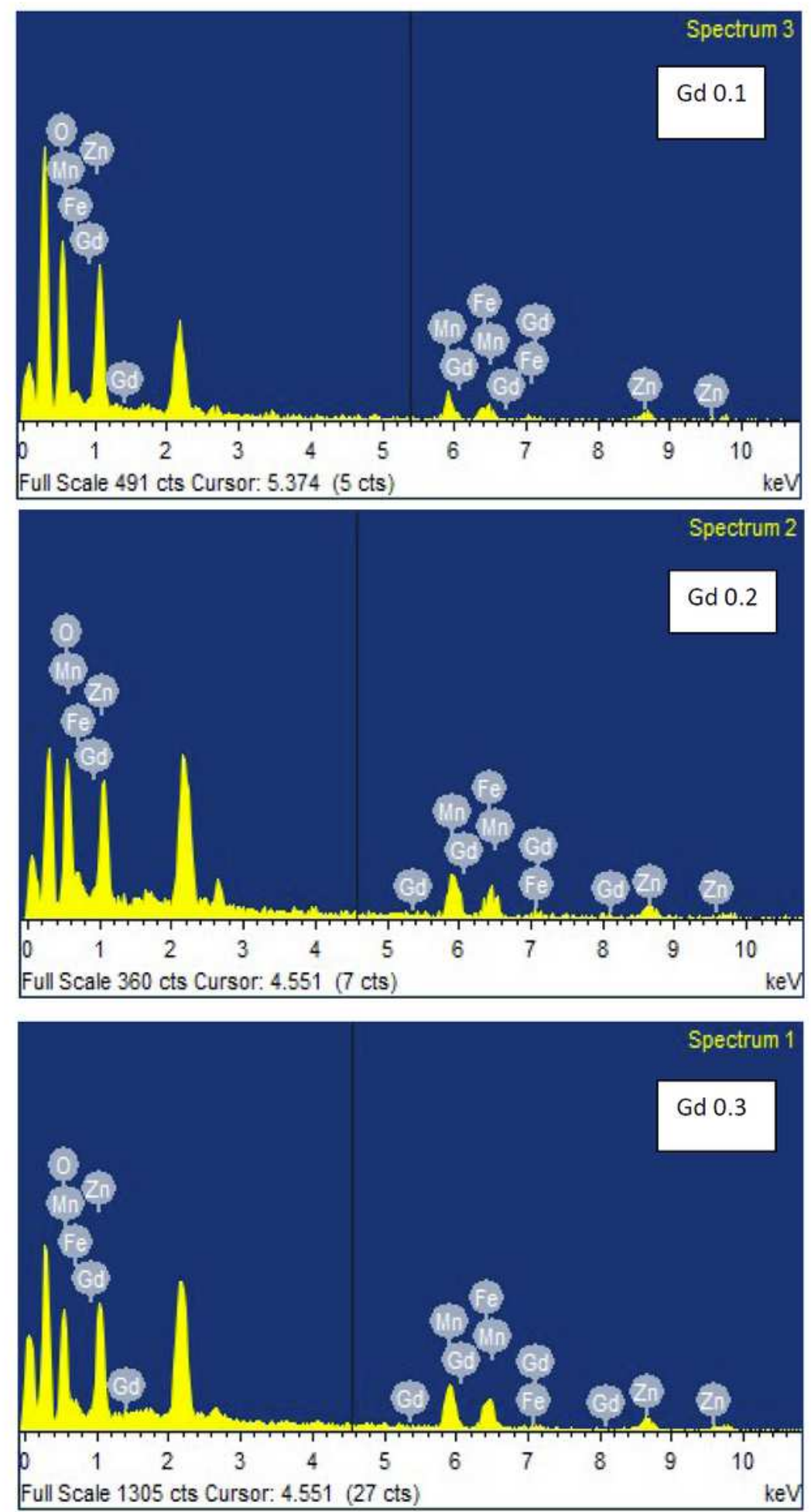

Figure 5

EDAX studies for pure and Gd doped Materials 


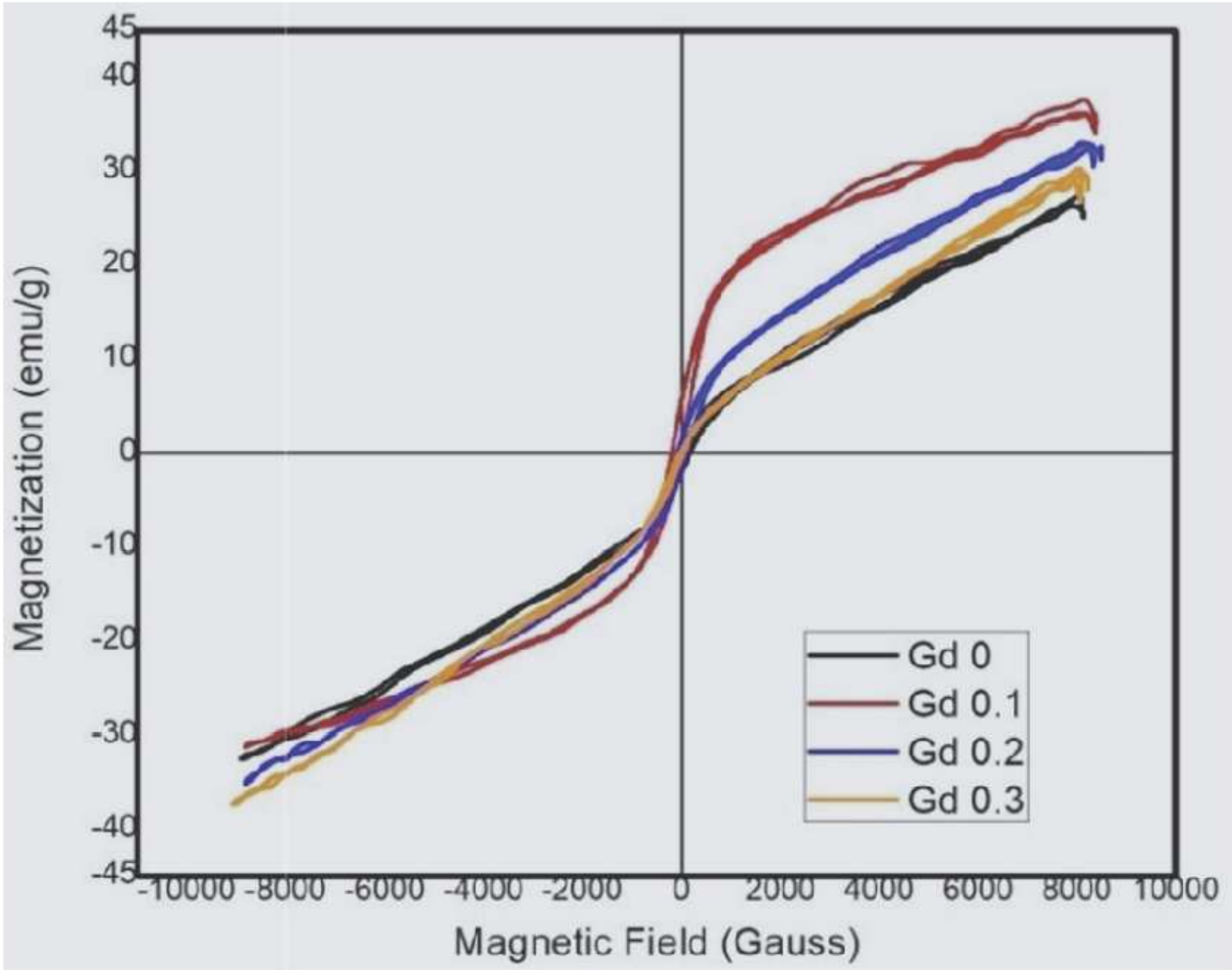

Figure 6

$\mathrm{M}-\mathrm{H}$ curve for as prepared samples 


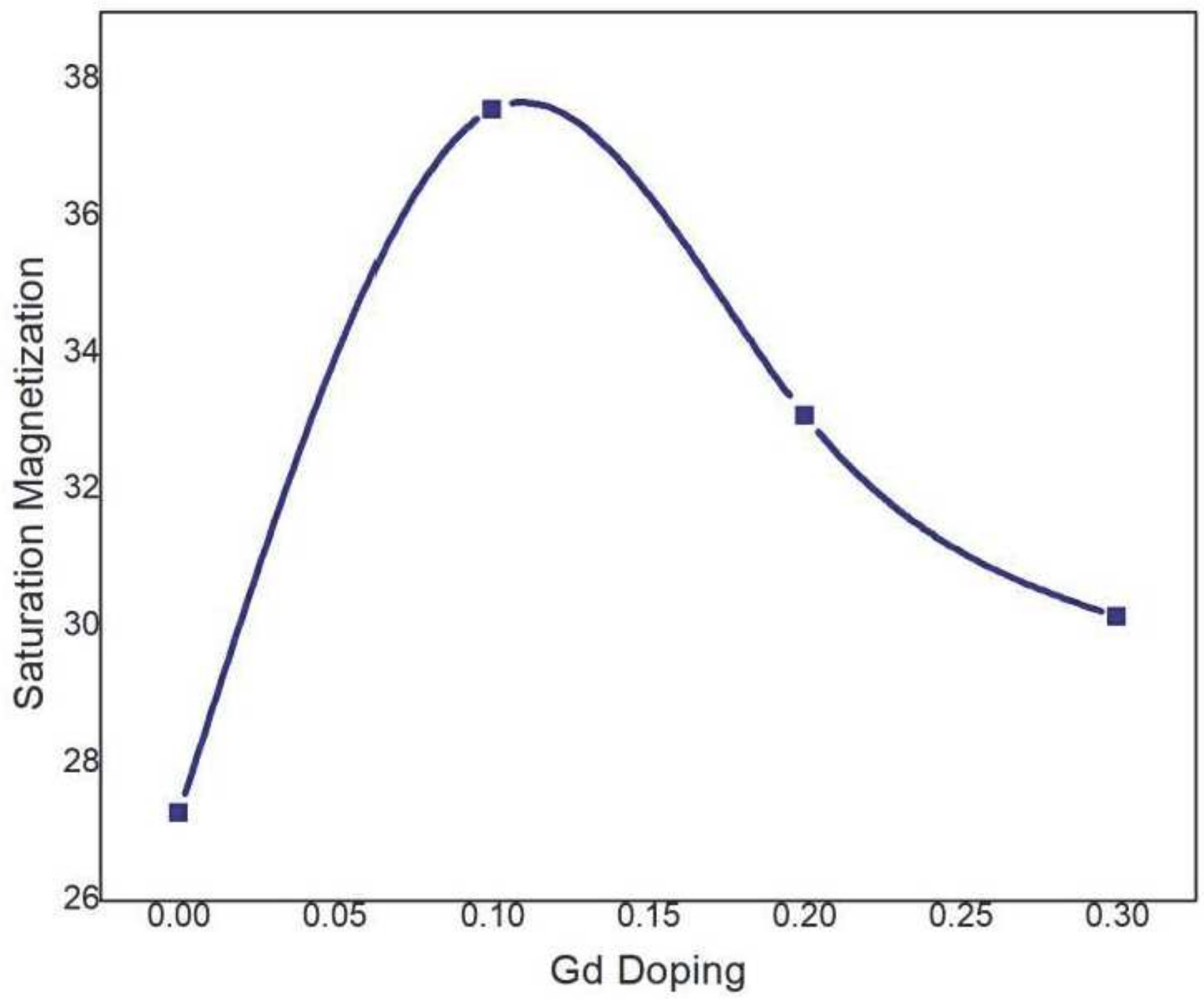

Figure 7

Concentration dependence of Saturation Magnetization 